\title{
Rotator Manșet Lezyonlarında Ultrasonografi Bulgularının Manyetik Rezonans Görüntüleme Sonuçları İle Karșılaștırılması
}

\author{
Comparison of the Ultrasound Findings with Magnetic Resonance Imaging in Rotator Cuff Lesions
}

\author{
Ayhan Yılmaz'1 , Tuğrul Örmeci², Ebru Yılmaz³3, Berrin Erok³, Mahir Mahiroğulları4, \\ Sibel Çağlar Atacan ${ }^{5}$, Doğuș Doğan ${ }^{6}$
}

Bahçelievler Devlet Hastanesi Radyoloji Bölümü

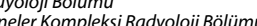
GOP Taksim Eğitim Araștırma Hastanesi Radyoloji Bölümü Medipol Üniversitesi Mega Hastaneler Kompleksi Ortopedi ve Travmatoloji Bölümü

${ }_{6}^{5}$ Adili Tip Kurumu
Geliș tarihi : 17.04.2015 • Kabul tarihi: 13.09.2015

iletișim

Dr. Ayhan Yılmaz

Tel: 05332230510

E-posta: dr_ayyilmaz@yahoo.com

Bahçelievler Devlet Hastanesi Radyoloji Bölümü İstanbul/Türkiye

Amaç: Omuz ağrısı șikayetiyle bașvuran hastalarda manyetik rezonans görüntüleme (MR) ile ultrasonografi (US) bulgularını karșılaștırarak rotator manșet lezyonlarında ultrasonografinin etkinliğini araștırdık.

Gereç-Yöntem: Omuz MR'ı çekilen 58 hastaya MR sonuçları görülmeden omuz ultrasonografisi yapıldı. US bulguları MR sonuçları ile karșılaștırılarak US'nin omuz ağrısı olan olgularda rotator manșet lezyonlarındaki duyarlılık ve özgüllük değerleri araștırıldı. İnfraspinatus ve subskapularis patolojileri sayıca yetersiz olup istatistiksel analiz güvenilirliğinin düșük olması nedeniyle sadece supraspinatus patolojileri değerlendirilmiștir

Bulgular: US ve MR bulguları karșılaștırıldığında supraspinatus tendonu tam kat yırtıklarında US'nin duyarlılık ve özgüllüğü \%95, parsiyel yırtıklarında duyarlılığı \%71,özgüllüğü ise \%98, supraspinatus tendinosis vakalarında duyarlılığı \%82,özgüllügü ise \%93' tür. .

Sonuç: US invaziv olmayan,ucuz,kolay ulașılabilen bir görüntüleme yöntemidir.Özellikle supraspinatus patolojisi düșünülen vakalarda yüksek duyarlılık ve özgüllük değerleri ile ilk görüntüleme yöntemi US olmalıdır.

Anahtar Sözcükler: Rotator Manșet Patolojileri, Omuz Ultrasonu, Manyetik Rezonans Görüntüleme

Aim: We searched the efficacy of ultrasound (US) for rotator cuff lesions by comparing the ultrasound findings with Magnetic Resonance Imaging (MRI) results in patients with shoulder pain.

Materials-Metods: Blinded to MRI results ;shoulder US was performed to 58 patients who had undergone MRI.MRI results were compared to US findings in patients with shoulder pain and rotato cuff pathologies.

Results: In the supraspinatus tendon;for full-thickness tears the sensitivity and specificity of US was $\% 95$,for partial tears the sensitivity was $71 \%$ and the specificity was $98 \%$,for supraspinatus tendinosis the sensitivity was $82 \%$,the specificity was $95 \%$. We could not do reliable statistical analysis becouse of insufficiant number of infraspinatus and subscapularis pathologies and so we evaluated only supraspinatus pathologies.

Conclusion: US is an non-invaziv, cheap and easly accessible imaging metod.Especially for the cases who we think that they have a supraspinatus pathologies the first imaging metod should be US due to its high sensitivity and specificity.

Key Words: Rotator Cuff Pathologies, Shoulder US, MRI

Omuz ekleminin insan vücudunun en hareketli, en çok kullanılan eklemlerinden biri olması ve içerdiği yumuşak dokuların yaşlanma ile birlikte ortaya çıkan dejenerasyonu nedeniyle bu eklemi ilgilendiren rahatsizlıklara sik rastlanmaktadır (1).

Omuz ağrisının en sik nedeni humerus başı ile korakoakromial ark elemanları arasında yer alan rotator manşet ve komşu bursanın sıkışmasıdır (1). Bu nedenle omuz ağrisı ve disfonksiyonu şikayetleriyle başvuran hastalarda rotator manşetin bütünlüğünün gösterilmesi çok önemlidir. Günümüzde bu amaçla ultrasonografi, BT- artrografi, konvansiyonel MR ve MRartrografi gibi pek çok görüntüleme yöntemi kullanılmaktadır.

Radyasyon içermemesi, kısa sürmesi, invaziv olmamas1, aynı seansta karşılaştırmalı inceleme sağlaması ve maliyetinin az olması gibi avantajları nedeniyle omuz ağrısı ve dis- 
fonksiyonu şikayetleriyle başvuran hastalarda öykü, fizik muayene ve direk grafiler sonrası ilk başvurulması gereken görüntüleme yöntemi ultrasonografi olmalıdır $(1,2)$. Biz bu çalışmamızda omuz ağrısı şikayetiyle başvuran 58 hastada MR sonuçları ile ultrasonografi bulgularını karşılaştırarak rotator manşet lezyonlarından en sik görülen supraspinatus patolojilerinde ultrasonografinin etkinliğini araştırdık.

\section{GEREÇ-YÖNTEM}

1 Nisan- 30 Mayıs 2008 tarihleri arasinda omuz ağris1 ve hareket kisitlilığ1 nedeniyle hastanemiz Radyoloji Kliniğine başvuran 58 hastayı çalışmamıza dahil ettik. Omuz ağrısı nedeniyle omuz MR'1 çekilen tüm hastalara omuz MR sonucundan habersiz ve bağımsız olarak aynı gün omuz ultrasonografi incelemesi yapild. Omuz MR ve ultrasonografi tetkikleri iki radyolog tarafindan değerlendirildi. Ultrasonografi bulguları MR sonuçlar1 ile karşılaştırılarak ultrasonografinin omuz ağrisı olan olgularda supraspinatus tendon patolojilerindeki sensitivite ve spesifisite değerleri araştırıldi. MR incelemede kalsifik tendinit şüphesi olan olgular dişında direk grafiler değerlendirilmemiştir.

Olguların 25’i erkek, 33'ü kadın, yaşları 14-80 arasinda olup ortalama 53.8'dir.

Ultrasonografik inceleme GE Logiq 9 cihazı ve 12L (10-14 MHz) lineer transduser ile yapılmıstır. İnceleme harmonik görüntüleme modunda gerçekleştirilmiş olup inceleme sırasinda geniş FOV (field of view) kullanılmasına dikkat edilmiştir. İnceleme sadece hastanın şikayeti olan omuzuna yönelik yapılmıştır. Kontralateral omuz çalışmaya dahil edilmedi. Hasta oturur pozisyonda iken kol adduksiyon, hiperekstansiyon ve internal rotasyona getirilerek (bu pozisyon hastaya elini arkadaki karşı cebine götürmesi istenerek anlatılabilir) supraspinatus tendonu longitudinal ve transvers planda değerlendirildi. Longitudinal inceleme; transduserin medialinde acromion, lateralinde tuberculum majusun laterali kalacak şekilde -transduser her zaman humerus baş1na dik konumda tutularak-önde biceps tendonu komşuluğundan başlayarak biceps tendonunun $2.5 \mathrm{~cm}$ lateraline kadar (bu düzeyde supraspinatus ile infraspinatus tendonları ortak insersiyosu görülmekte) devam edilerek yapıld1. Transvers inceleme; acromion lateralinden supraspinatus tendonu boyunca-transduser tendona dik konumda tutularak- aşağıda tuberculum majusa kadar yapıldı. Tüm inceleme süresi 20 dakikayı aşmadı.

Manyetik rezonans görüntüleme Siemens Avanto 1.5 Tesla MR cihazı ile gerçekleştirildi. Hasta supin pozisyondayken 8 kanallı omuz koili ile görüntüler alındı. Tüm hastalarda axial, koronal, sagittal plan yağ baskılı proton ağırlıklı turbo spin eko (PD TSE), koronal T2 ağırlıklı TSE ve sagittal plan T1 ağırlıklı TSE sekanslar kullanıldı.

Supraspinatus tendonun izlenmemesi veya tendonda devamsizlik tam kat yırtık,tendonun artiküler veya bursal yüzüne sinırlı fokal defekt parsiyel yırtık,tendonda diffüz kalınlaşma tendinozis ile uyumlu değerlendirilmiştir.

Tablo 1: Supraspinatus tendon patolojilerinde US-MR karşılaştırması

\begin{tabular}{|c|c|c|c|c|c|c|c|c|c|}
\hline \multirow{2}{*}{ SUPRASPINATUS } & \multicolumn{3}{|c|}{ US(toplam) } & \multicolumn{5}{c|}{ US } \\
\cline { 3 - 12 } & \multicolumn{2}{|c|}{$\begin{array}{c}\text { Tam Kat } \\
\text { Yırtık }\end{array}$} & \multicolumn{2}{|c|}{ Parsiyel Yırtık } & \multicolumn{2}{|c|}{ Tendinosis } \\
\cline { 2 - 11 } & $\begin{array}{c}\text { Patoloji } \\
\text { var }\end{array}$ & patoloji yok & Var & Yok & Var & Yok & Var & Yok \\
\hline \multirow{2}{*}{ MR } & + & 50 & 2 & 19 & 1 & 10 & 4 & 14 & 3 \\
\cline { 2 - 12 } & - & 0 & 6 & 2 & 36 & 1 & 43 & 3 & 38 \\
\hline
\end{tabular}

Tablo 2: Supraspinatus tendon patolojilerinde MR sonuçlarına göre ultrasonografinin istatistiksel analizi

\begin{tabular}{|c|c|c|c|c|}
\hline \multirow{2}{*}{ SUPRASPINATUS } & \multirow{2}{*}{ US(toplam) } & \multicolumn{3}{|c|}{ US } \\
\cline { 3 - 5 } & & Tam Kat Yırtık & Parsiyel Yırtık & Tendinosis \\
\hline Özgüllük (\%) & 100 & 95 & 98 & 93 \\
\hline Doğruluk (\%) & 97 & 95 & 91 & 90 \\
\hline $\begin{array}{c}\text { Pozitif Kestirim } \\
\text { Değeri (\%) }\end{array}$ & 100 & 90 & 91 & 82 \\
\hline $\begin{array}{c}\text { Negatif Kestirim } \\
\text { Değeri (\%) }\end{array}$ & 75 & 97 & 91 & 93 \\
\hline
\end{tabular}




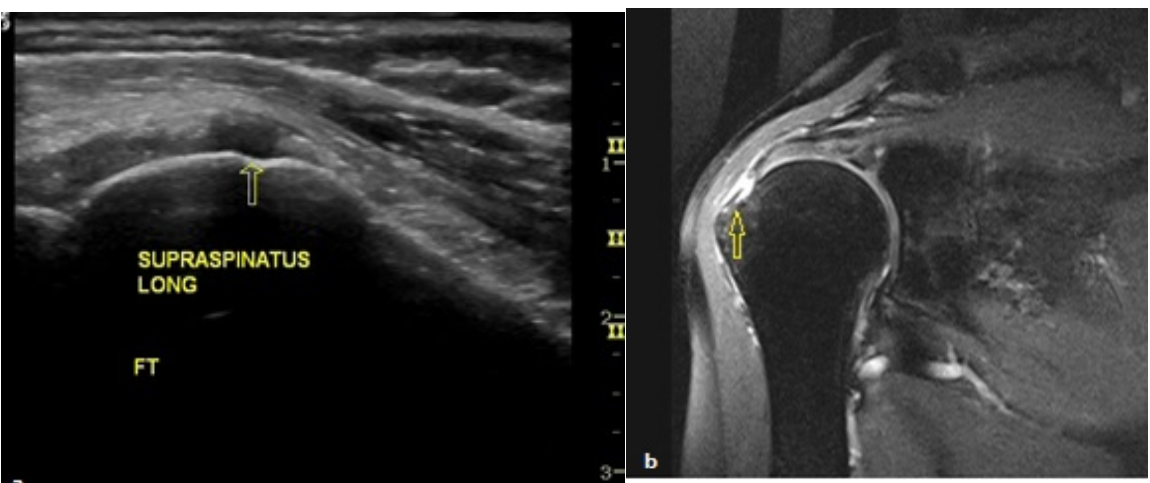

Şekil 1: Ultrasonografi imajında (a) suprapinatus tendon distal kesimde tam kat yırtık ile uyumlu fokal hipoekoik alan (ok), aynı olgunun koronal plan PD TSE FS MR imajında (b) tam kat yırtık (ok) görülüyor

Ultrasonografi, manyetik rezonans görüntüleme ile parsiyel yırtık tanısı alan 14 olgunun 10'unu saptarken 1 olguyu tam kat yırtık, 3 olguyu ise tendinosis olarak değerlendirmiştir. Ultrasonografinin parsiyel yırtık olarak değerlendirdiği 1 olgu MR incelemede tam kat yırtık tanısı almıştır. Ultrasonunun supraspinatus tendonu parsiyel yırtıklarında duyarlılığ1 \%71, özgüllüğü ise \%98'dir (Şekil 2).

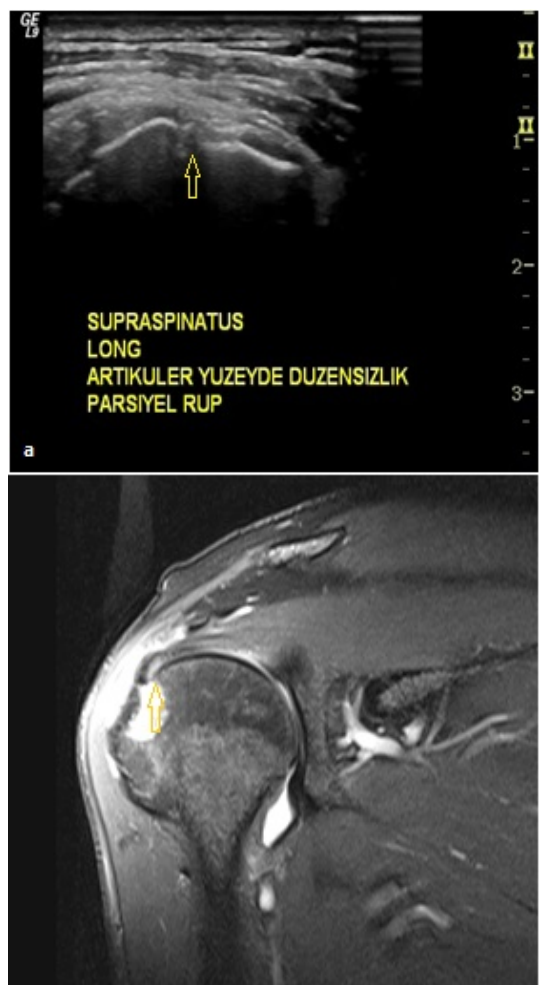

Şekil 2: Ultrasonografi imajında(a) suprapinatus tendon distal kesim artiküler yüzde parsiyel yırtık ile uyumlu düzensizlik(ok), Koronal plan PD TSE FS MR imajda (b) supraspinatus tendonu distal artiküler yüzde parsiyel yırtık(ok), subdeltoid effüzyon ve humerus başında dejeneratif değişiklikler görülüyor
Ultrasonografi, manyetik rezonans görüntüleme ile tendinosis tanısı alan 17 olgunun 14'ünü saptarken 1 olguyu tam kat yırtık,2 olguyu ise normal olarak değerlendirmiştir. Bunun dişında ultrasonografinin tendinosis olarak yorumladığ 3 vaka ise MR incelemede parsiyel yırtık tanısı almıştır. Ultrasonun supraspinatus tendinosis vakalarında duyarlılığ1 \%82, özgüllüğ̈u ise \%93' tür (Tablo 2).

Hem ultrasonografi hem de manyetik rezonans görüntüleme 6 vakayı normal bulmuştur. Bunun dişında ultrasonografinin normal olarak değerlendirdiği 2 vaka MR incelemede tendinosis tanısı almıştır.

MR incelemede PD TSE sekansinda belirgin hipointens sinyal özelliği ile supraspinatus tendonu yapışma düzeyinde kalsifik tendinit düşünülmüş, direk grafi ile tanı doğrulanmıştır. Bu olgu ultrason ile de saptanmış olup bunun dişında ultrasonun yanlış pozitif ya da yanlış negatif olgu değerlendirmesi olmamıştır.

Ultrasonografi ile görülebilen rotator manşet yırtıklarına eşlik eden bulgular; subdeltoid bursal ya da eklem içi effüzyon, subdeltoid yağ konturunda konkav görünüm ve kemik yüzeyinde düzensizliktir. Bizim çalışmamızda da rotator manşet yırtığına en fazla eşlik eden bulgu subdeltoid bursal effüzyondur. Supraspinatusta tam kat yırtık görülen yirmi vakanın onyedisinde subdeltoid bursal effüzyon görülmüştür. Subdeltoid bursal effüzyon görülen olgularin sadece bir tanesinde rotator manşet yırtığı saptanmamıştır (Şekil 3).

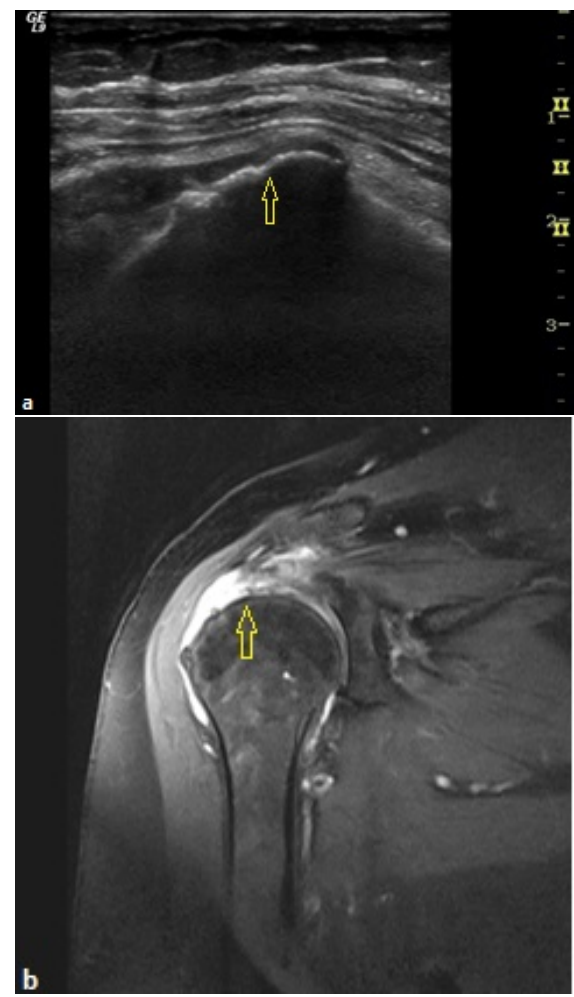

Şekil 3: Ultrasonografi imajında (a) suprapinatus tendon distal kesimde seçilemiyor (ok), tam kat yırtık ile uyumlu, Koronal plan PD TSE FS MR imajında (b) supraspinatus tendonunda retrakte (ok) tam kat yırtık görülüyor

Yaşa göre supraspinatus patolojileri arasındaki farklılığa baktığımızda; tam kat yırtık görülen olgular normal ve tendinosis görülen olgulara göre daha yaşlı iken $(\mathrm{p}<0.05)$, tam kat yırtık ile parsiyel yırtık görülen olguların yaşları arasinda anlamlı fark bulunmamaktadır.Yine parsiyel yırtık ve tendinosisli olgular normallere göre daha yaşlı bulunmuştur $(\mathrm{p}<0.05)$.

Supraspinatus tendon patolojilerinin geneline bakacak olursak (tablo 1) ultrasonografinin duyarlılık ve özgülüğü yüksektir. Bu da ultrasonografinin supraspinatus patolojileri için olguların tümünde hasta ve sağlamları yüksek ayırt etme gücüne sahip olduğunu gösterir.

\section{TARTIȘMA}

Omuz ağr1sı kas-iskelet sisteminin en s1k karşılaşılan semptomlarından biridir (1). Klinik ve fizik-muayene bulguları rotator manşet patolojilerinin teşhisi için spesifik değildir. Yani bu bulgu- 
larla tam kat yırtık, parsiyel yırtık ya da tendinozis ayırımı yapilamaz. Tam kat yırtığ1 olan hasta asemptomatik olabilirken veya hafif bir ağrı tariflerken tendinozisli olguda hareket k1sitl1lığ1 ve şiddetli ağrı olabilir. Bu nedenle omuz ağrisı olan olgularda tanı koymak amaciyla görüntülemeye ihtiyaç duyulmaktadır (1).

Omuz ultrasonografisi ilk kez 1979 yilında Seltzer tarafindan artrografiye alternatif olarak uygulamaya konuldu (3). Ultrasonografi non-invazif, dinamik ve ucuz bir görüntüleme tekniğidir (2).

Rotator manşet yırtığ1 olan hastalarda konvansiyonel grafiler genellikle normal olmakla birlikte ilk tercih olmalıdır. Kronik rotator manșet yırtıklarında direk grafilerde, sekonder bulgular görülebileceği gibi, omuz ağrısı yapabilecek kemik patolojileri de aranmalıdır. Bu nedenle hastalar rotator manşet yırtığı ön tanısıyla ultrasonografik incelemeye yönlendirilmeden önce, omuz ağrısı yapabilecek kemik patolojileri ve olası akciğer apikal lezyonlarını (örneğin pancoast tümörünü) ekarte etmek amaciyla mutlaka direk grafiler değerlendirilmelidir $(1,2)$.

Artrografinin omuzda ağrı ve hareket kısıtlılığının değerlendirilmesinde önemli rolü olduğu düşünülmektedir. Ancak artrografi invaziv bir işlemdir ve bir takım yan etkileri olabilmektedir (4). Risklerden dolayı ve omuzda oluşan reaktif ağrilar nedeniyle rotator manşet yırtığını tespit etmek için öncelikle non-invaziv görüntüleme yöntemi olan ultrasonografi denenebilir (2).

Ultrasonografi omuz bölgesinde en çok rotator manşet patolojileri için kullanılmaktadır. Rotator manşeti değerlendirirken; tendonun normal olup olmadığını, anormalse bulgunun tendinozis mi yoksa yırtık lehine mi olduğunu, yırtıksa tam kat mi yoksa parsiyel yırtık mi olduğunu, retraksiyonun eşlik edip etmediğini belirtmek gerekir (2).

Ultrasonografide rotator manşet tam kat yırtık kriterlerini rotator manşetin hiç izlenmemesi, fokal bir alanda görül- memesi, manşette devamsızlık olarak sıralayabiliriz (2,5). Çalışma grubumuzda manşetin hiç görülmediği olgular tam kat retrakte yırtık, fokal bir alanda görülmeyen veya manşette devamsızlık görülen olgular retrakte olmayan tam kat yırtık bursal veya artiküler yüzde defekt-volüm kaybı parsiyel yırtık ve fokal anormal ekojenite ise tendinosis lehine değerlendirilmiş olup MR sonuçları ile karşılaştırdığımizda sonografik tanımlamaların klinik bulgular ve MR ile uyumlu olduğu görülmüştür (Tablo 1).

Çalışmamızda da olduğu gibi tam kat ve parsiyel yırtığa eşlik eden en güvenilir bulgu subdeltoid bursal effüzyondur (Şekil. 3). Hollister ve ark. (6) bursal effüzyonun rotator manşet yırtıkları için spesifitesini \%96 olarak bulmuştur. Rumack ve ark. (7) da bursal s1vis1 olan tüm vakalarda rotator manşet yırtığ1 tespit etmişlerdir.

Rumack ve ark. nın (7) yapmış oldukları çalışmada yaşla birlikte rotator manşette yırtık görülme riskinin arttığı belirtilmiştir. Bizim çalışmamızda da rotator manşette yırtık görülme riski beşinci dekattan sonra artış göstermekle birlikte rotator manşette yırtık görülen olguların yaşları tendinozisli ve normal olgulara göre daha yüksek bulunmuştur.

Çalışmamızda olguların travma, hareket k1sıtlllı̆g1 öyküleri ve cinsiyeti ile supraspinatus patolojileri arasinda anlam11 fark saptanmamıştır.

Ultrasonografinin rotator manşet lezyonlarındaki özgüllük ve duyarlılığını araştıran yayınlarda bizim çalışmamızda olduğu gibi en çok supraspinatus patolojisi saptanmıştır (8). Dolayısiyla yayınlarda bildirilen duyarlilık ve özgüllük değerleri supraspinatus patolojileri göz önünde bulundurularak hesaplanmıştır. Bu çalışmada da infraspinatus ve subskapularis patolojileri sayıca yetersiz olup istatistiksel analiz güvenilirliğinin düşük olması nedeniyle sadece supraspinatus patolojileri değerlendirilmiştir.

Ultrasonografinin tam kat supraspinatus yırtıkları için literatürde bildirilen duyarlılık ve özgüllük değerleri sırasıyla $\% 57-100$ ve $\% 50-100$ arasinda de- ğişmektedir (5,9-11). Düşük oranlar kullaniciya ve ultrasonografi-prob gibi teknik faktörlerin yetersizliğine bağlanabilir. Son zamanlarda deneyimli araştırmacıların yeni ultrasonografi cihazları ile yaptıkları çalışmalar sonucu tam kat yırtıklarda doğruluk \%96, duyarlllık \% 100, özgüllük \%85 gibi yüksek değerlere ulaşmıştır (1214). Parsiyel yırtıklarda ise bu oranlar duyarlılık ve özgüllük için sırasıyla $\% 93$ ve $\% 94$ tür (15). Bizim çalışmamizda ultrasonografi, 20 tam kat yirtık olgusunun (Şekil 1)19'unu, 14 parsiyel yırtık olgusunun (Şekil 2) 10’unu doğru tespit etmiştir. Tam kat yırtık için doğruluk, duyarlılık ve özgüllük değerleri \%95, parsiyel yırtık için doğruluk $\% 91$, duyarlilik $\% 71$ ve özgüllük ise $\% 98$ olarak bulunmuştur. Ultrasonografi tam kat yırtıklarda parsiyel yırtıklara nazaran daha doğru sonuç vermekle birlikte her iki patolojide de duyarlılık ve özgüllük değerlerinin yüksek oluşu omuz patolojilerinde tanı aracı olarak kullanılabileceğini göstermektedir(16-18).

Çalışmamız sonucunda rotator manşet lezyonlarında ultrasonografinin negatif kestirim değeri (\%50) düşük çıkmiştır. Bu sonuç çalışma grubumuzdaki normal olgu sayısının azlığı göz ardı edilecek olursa, ultrasonografinin normal dediği olguların klinik şüphe halinde ileri tetkikine gerek duyulacağını göstermektedir.

MR incelemede supraspinatus ve subscapularis tendonlarında kalsifikasyon görülen ve kalsifik tendinit tanısı alan birer vaka ultrasonografik olarak da doğru tanımlanmıştır.

Ultrasonografinin en büyük dezavantaj1 kullanıcıya bağımlı olmasıdır. Doğru tanı koymak tecrübe ve bilgi birikimi gerektirdiği gibi aynı zamanda kullanılan ultrasonografi cihazının da teknik açıdan yeterli olması gerekir. Obezite ve hareket kisitlilığ1 da ultrasonografik incelemeyi zorlaştırarak tanı değerini düşürmektedir. Ultrasonografinin diğer bir dezavantaji ise omuz eklemini oluşturan kemik yapıları, labrumun tamamını ve ligamanları görüntüleyememesidir. Ultrasonografi ile rotator manşet tendonlarını, biceps tendonunu ve eklem içi effüzyonu görebiliriz. 


\section{SONUÇ OLARAK;}

Omuz ağr1sı ve fonksiyon bozukluğu olan hastalarda tanı için günümüzde en sık kullanılan görüntüleme yöntemi MR incelemedir. Omuz bölgesinde ultrasonografinin kullanım endikasyonu ve amacı en sık omuz ağrisı

\section{KAYNAKLAR}

1. D.Stoller,Magnetic Resonance Imaging in Orthopaedics and SportsMedicine,Lipincott Williams-Wilkins,3rd edition,2007;1324-1364

2. Teefey SA, Middleton WD, Yamaguchi K. Shoulder sonography. State of the art. Radiol Clin North Am. Jul 1999;37(4):767-85

3. Seltzer SE, Finberg HJ, Weissman BN, Kido DK, Collier BD: Arthrosonography: Gray-scale ultrasound evaluation of the shoulder. Radiology 1979;132: 467-468

4. FM Hall, DI Rosenthal, RP Goldberg, and $G$ Wyshak. A prospective study was performed to assess patient discomfort after shoulder arthrography,AJR Am J Roentgenol 1981;136:59

5. Wiener SN, Seitz WH Jr. Sonography of the shoulder in patients with tears of the rotator cuff: accuracy and value for selecting surgical options. AJR Am J Roentgenol. Jan 1993;160(1):103-7; discussion

6. Hollister MS, Mack LA,Pattern RM; Association of sonographically detected subacromial/subdeltoid bursal effusion and intraarticular fluid with rotator cuff tear.AJR 1995;165:605-608 nedenlerinden olan rotator manşet lezyonlarını görüntüleyip tanı koymak ve gerekirse ileri tetkike yönlendirmektir. MR gibi pahalı ve artrografi gibi invaziv görüntüleme yöntemlerini kullanmadan ultrasonografi ile birçok vakaya tanı koyabiliriz. Omuz ağrisının sıklığ1 ve MR incelemenin pa- halı olması göz önüne alındığında rotator manşet lezyonlarının tanısında sonografik inceleme yüksek doğruluk, duyarlılık, özgüllük değerleri ve avantajları nedeniyle tanıda başvurulacak ilk yöntem olmalıdır.
7. C.Rumack, Diagnostic Ultrasound, 3rd edition, 2005;898-900

8. Crass JR,Craig EV,Feinberg SB: Ultrasonography of rotator cuff tears:A review of 500 diagnostic cuffs.J Clin Ultrasound 1988;16:313-327

9. Brandt TD, Cardone BW, Grant TH, et al. Rotator cuff sonography: a reassessment. Radiology. Nov 1989;173(2):323-7

10. Mack LA, Gannon MK, Kilcoyne RF, Matson FA 3rd. Sonographic evaluation of the rotator cuff. Accuracy in patients without prior surgery. Clin Orthop. Sep 1988;(234):21-7

11. Soble MG, Kaye AD, Guay RC. Rotator cuff tear: clinical experience with sonographic detection. Radiology. Nov 1989;173(2):319-21

12. Geoff Hide,Shoulder,Rotator cuff injury (ultrasonography),e-medicine

13. Teefey SA, Hasan SA, Middleton WD, et al. Ultrasonography of the rotator cuff. A comparison of ultrasonographic and arthroscopic findings in one hundred consecutive cases. J Bone Joint Surg Am. Apr 2000;82(4):498-504
14. Teefey SA, Middleton WD, Yamaguchi K. Shoulder sonography. State of the art. Radiol Clin North Am. Jul 1999; 37(4): $767-85$

15. Van Holsbeeck MT, Kolowich PA, Eyler WR, et al. US depiction of partialthickness tear of the rotator cuff. Radiology. Nov 1995;197(2):443-6.

16. Naqvi GA, Jadaan M, Harrington P. Accuracy of ultrasonography and magnetic resonance imaging for detection of full thickness rotator cuff tears. Int J Shoulder Surg. 2009 Oct-Dec; 3(4): 94-97

17. Roy JS,Braen C,Leplond J,et al. Diagnostic accuracy of ultrasonography, MRI and MR arthrography in the characterisation of rotator cuff disorders: a meta-analysis. British Journal of Sports Medicine $\mathrm{Br} J$ Sports Med doi:10.1136/bjsports-2014094148

18. Tefeey SA, Petersen B,Prather $\mathrm{H}$,et al. Shoulder Ultrasound vs MRI for Rotator Cuff Pathology. Physical medicine and Rehabilitation .2009 May;1:490-495. 
